SHIFTING GEARS FOR THE AUTOMATED VEHICLE: FINDINGS FROM FOCUS GROUPS IN THE GREATER TORONTO AND HAMILTON AREA

\author{
by \\ Élyse Comeau \\ BA, University of Toronto, 2015 \\ A Major Research Paper \\ presented to Ryerson University \\ in partial fulfillment of the requirements for the degree of \\ Master of Planning \\ in \\ Urban Development
}

- Toronto, Ontario, Canada, 2018

(C) Élyse Comeau, 2018 
I hereby declare that I am the sole author of this MRP. This is a true copy of the MRP, including any required final revisions.

I authorize Ryerson University to lend this MRP to other institutions or individuals for the purpose of scholarly research.

I further authorize Ryerson University to reproduce this MRP by photocopying or by other means, in total or in part, at the request of other institutions or individuals for the purpose of scholarly research.

I understand that my MRP may be made electronically available to the public. 


\title{
SHIFTING GEARS FOR THE AUTOMATED VEHICLE: FINDINGS FROM FOCUS GROUPS IN THE GREATER TORONTO AND HAMILTON AREA
}

\author{
C Élyse Comeau, 2018 \\ Master of Planning \\ in \\ Urban Development \\ Ryerson University
}

\begin{abstract}
The emergence of automated vehicles (AVs) may potentially transform the ways in which individuals travel, and integrating the impacts and opportunities of AVs into travel demand forecasts and transportation planning will be important for wise decision-making. This paper presents findings from focus groups designed to explore Greater Toronto and Hamilton Area (GTHA) residents' interest and responses to AVs. Results suggest that the general public is interested in AVs and eager to learn more, and that individual travel habits carry significant weight. The findings from this study emphasize the planner's responsibility to engage in consultations internally, within organizations and across departments, as well as externally, with stakeholders and members of the community. On-going internal and external engagements will first allow organizations to prepare and consolidate appropriate strategies for this disruptive technology, and second, will keep the public sphere informed and engaged in the implementation of AVs.
\end{abstract}

Key words: automated vehicles, planning, transportation, travel behaviour, focus groups. 


\section{ACKNOWLEDGEMENTS}

The focus group findings presented in this article are based on work conducted by the primary author, Leah Birnbaum, Tyler Olsen, and Matthias Sweet through Ryerson University's Transportation and Land Use Research Laboratory. This research was funded by the City of Toronto, Metrolinx, and the Centre for Urban Research and Land Development (CUR). Thanks should also be extended to the focus group participants who dedicated their time and energy to this initiative. 


\section{TABLE OF CONTENTS}

1. INTRODUCTION .............................................................................................................................. 1

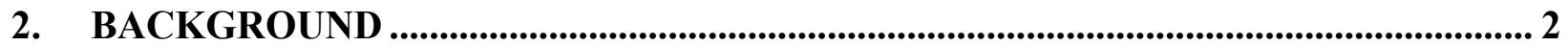

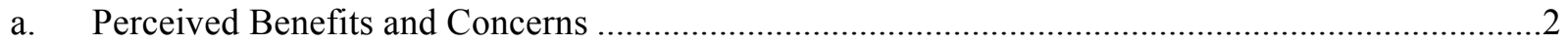

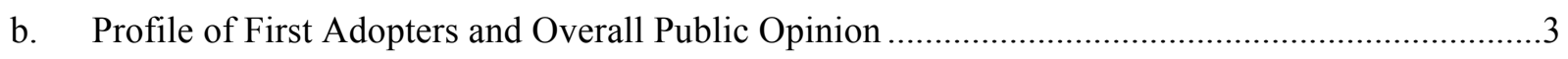

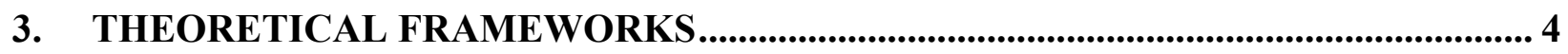
a. Utility
b. Habit Formation

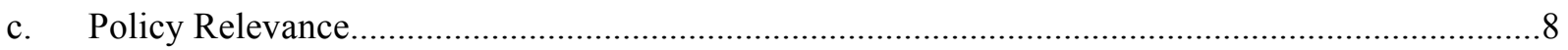

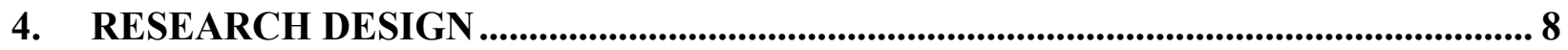

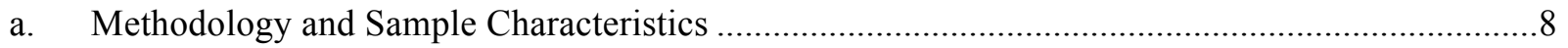

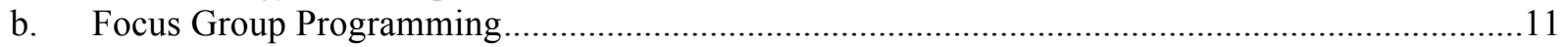

5. RESULTS .................................................................................................................................... 12

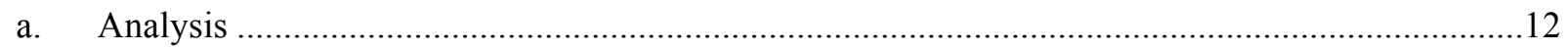

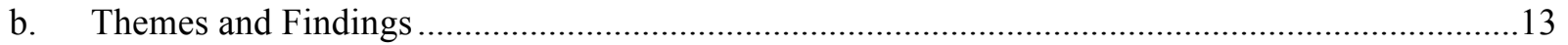

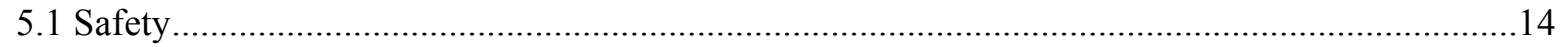

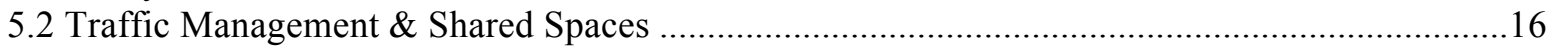

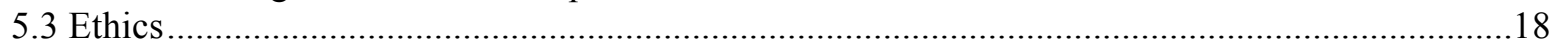

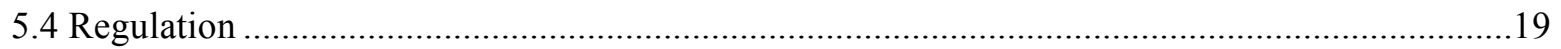

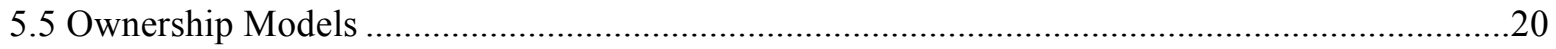

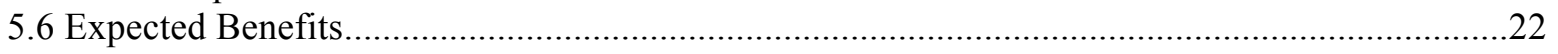

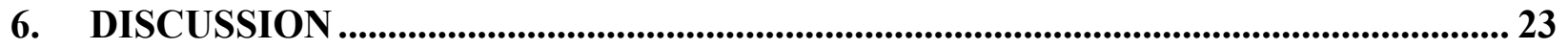

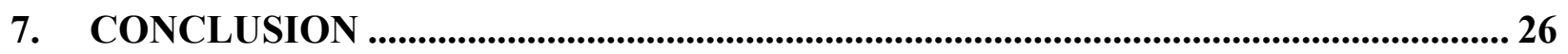

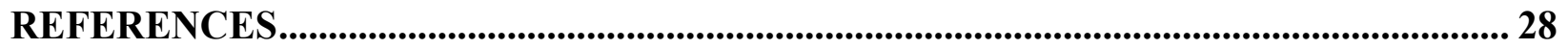




\section{INTRODUCTION}

New economies and emerging technologies are constantly reshaping the urban landscape of cities. Automated vehicles (AVs) may change the way residents in the Greater Toronto Hamilton Area (GTHA) travel, and thus holds the potential to modify the physical, social, and economic fabric of Toronto and its surrounding regions. Transportation planning could benefit from leveraging automated technologies where they relate to shared mobility and intermodal transit, thus creating opportunities for cities to become increasingly interconnected.

The quantitative models utilized in transportation planning practices face limitations when informing plans and policies, as they assume that humans possess extensive knowledge of all alternatives (Simon, 1955). In reality, citizens are not feasibly able to collect, process and compute the wide range of utilities and information when faced with every decision (Adjei \& Behrens, 2012). Therefore, dedicating more time to understand the ways in which decisions are made in relation to travel behaviour is of upmost importance. Focus groups exploring public opinion of AVs in the GTHA were conducted in order to better understand the potential impact of this technology for residents in the region.

This paper is divided into seven sections. Following the introduction, the second section provides a brief overview of literature on automated vehicles and highlights the public's major questions and concerns on the topic. The third section introduces the theoretical frameworks of utility and habit formation in transportation planning, specifically as they relate to travel behaviour and policy making in preparation for AVs. The fourth section discusses the research method and approach, and the fifth section presents the focus group findings using synthesized 
themes. Through a discussion of the results, the final sections provide recommended approaches and responsibilities for planners and policymakers in preparing for automated vehicles.

\section{BACKGROUND}

Though the regulatory context and the implications of AVs on the physical landscape and travel behaviour remain unclear, the benefits of AVs have the potential to be significant (Bansal et al., 2016; LaMondia et al., 2016). The following recurring themes in research are found to strongly influence perceptions and user acceptance of AVs: gender; income; age; convenience; and safety.

\section{a. Perceived Benefits and Concerns}

Potential benefits of automated vehicles range from reduced greenhouse gas emissions, lower demand for parking infrastructure, increased road safety (reduced road accidents caused by human error), and increased accessibility for individuals with physical or psychological mobility issues (Alessandrini et al., 2015; Daziano et al., 2016). In addition, benefits such as fuel and parking savings, as well as reduced commute times could potentially represent $\$ 2,000$ in savings per active AV in annualized costs (Bansal \& Kockelman, 2015). When AVs become more widely used, savings are projected to double (Bansal \& Kockelman, 2015).

A large proportion of academic work on AVs reveal that many participants in survey and focus group research express concerns around software hacking, misuse, and legal issues relating to accident accountability (Kyriakidis et al., 2015). The public questions who will be held responsible in the case of an accident, whether the accident involves a collision with another vehicle or a pedestrian (Robertson et al., 2016), and who will be held liable in the case of 
equipment or system failures (Bansal et al., 2016; Yim, 1997). Due to the nature of this emerging field, questions relating to the regulatory oversight and legal liability of AVs will be assessed on a case-by-case basis. There are also concerns relating to market demand and cost (i.e. affordability).

Others have highlighted the potential concerns of AVs in relation to individuals who do not choose to adopt this technology (i.e. reduced expenditures in public transit services, reduced street space allocation for bike lanes, etc.) (Litman, 2018). The widespread adoption of AVs could potentially increase traffic as more cars would be sharing the road, but could also decrease traffic if large proportions of the population begin sharing rides and adopting carpooling models (Litman, 2018). As such, the outcome for AVs appears to depend very closely on how these vehicles will be used.

\section{b. Profile of First Adopters and Overall Public Opinion}

While the direct implications of AVs on travel behaviour remain uncertain, some speculation on early adopters is emerging. An internet-based survey on public opinions of AVs found that urban, high-income tech-savvy males are most interested in the adoption of automated technologies in their day-to-day lives (Bansal et al., 2016). Another finding consistent with previous ride-sharing research indicates that citizens who live in densely populated urban neighbourhoods are more likely to adopt AVs (Bansal et al., 2016). Studies also indicate that individuals who drive more often are willing to pay higher amounts for automated technologies (Kyriakidis et al., 2015).

Past research suggests that the willingness to pay for AVs is correlated with age, gender, 
and income (Bansal et al., 2016). In general, studies focusing on the public's opinion of AVs find that younger males living in urban areas, who are also regular drivers are more willing to adopt AVs, and have a higher willingness to pay for automated technologies (Olsen et al., 2018; Bansal et al., 2016). Other studies suggest that males are more likely than females to prefer automation, but age does not play a significant role (Zmud et al., 2016). In addition, findings from research suggest that in some cases, older individuals are less willing to adopt AVs (Bansal \& Kockelman, 2015)

While the majority of research on automated vehicles has been concerned with the opinions of drivers, studies have also identified the importance of consulting non-drivers in relation to the emergence of AVs (Nordoff et al., 2016). Understanding the needs of public transit users and other active transportation options such as walking and cycling will allow academics, professionals, and policymakers alike to develop a comprehensive understanding of public perceptions of AVs, which will in turn inform the strategies for their implementation.

\section{THEORETICAL FRAMEWORKS}

Transportation planning processes are organized around evidence-based decision support systems based on significant quantitative travel demand data. The following section explores the existing framework under which transportation planning occurs, subsequently introducing habit formation theory as a potentially rigorous and complimentary approach in assessing prospective behavioural adoption to inform decision-making.

Planning practitioners attempt to understand individual travel decision-making based on two theories: utility theory and habit formation theory. In assuming that travel behaviour matters 
for planning outcomes, it may be important to engage both theories to understand the process of acceptance regarding new technologies when formulating plans and policies. In so far that transportation planning is interested in travel behavior, the ways in which planners understand and operationalize the latter in their work is important.

\section{a. Utility}

While the assumed benefits of automated vehicles are highly probable, they have been formulated on best case scenario projections derived from utility theory with the assumption that humans make rational decisions at all times, thus ignoring human error and bias. Influenced by the work of philosopher and political radical Jeremy Bentham in the $19^{\text {th }}$ century, the principle of utilitarianism is premised on an empiricist account of human nature, where all things humans do, say, and think are governed by the standard of 'right' and 'wrong' (Bentham, 1890, p. 5).

The models utilized in transportation planning practices are utilitarian in nature. However, utility theory faces limitations when informing plans and policies, as it assumes that humans possess extensive knowledge of all alternatives in order to rank them according to their utilities (Simon, 1955). In general, individuals only think in terms of their next trip by analyzing the marginal cost of gas and parking versus transit fare. Profoundly influenced by their environments, humans have limited cognitive abilities, and tend to select the alternative with the utmost immediate appeal, at the cost of long-term happiness and greatest utility (Thaler \& Sunstein, 2009; Kahneman, 2011). Therefore, the exclusive reliance on normative theories by planners - especially in preparation for AVs - may lead to systematic errors in forecasting consumer choices and travel behaviour. 


\section{b. Habit Formation}

Growing empirical evidence emphasize the significant role of habits in guiding decisionmaking processes in relation to travel behaviour (Brette et al., 2014). This perspective sheds light on the shortcomings and limitations of traditional utility based theories in their understanding of human decision-making. Specifically, in order to initiate a change in transportation behaviour, policies must be developed with a comprehensive understanding of the habituation processes, rather than adopting the assumption of reasoned action (Brette et al., 2014; Ajzen, 1991). Defined as "learned sequences of acts, aimed at obtaining certain goals or end states," habits become natural and automatic responses to particular situations and environments (Adjei \& Behrens, 2012, p. 58). Simplified, the logic underlying the theory of habit formation contends that the more repetitive the activity or action, the stronger the formation of the habit.

Evidence from travel behaviour analyses are particularly compelling in support of habit formation theory, specifically the relation between the habit of car-use and other habits associated with driving (i.e. listening to music, observing the scenery, and speaking on the phone) (Brette et al., 2014). The associated theoretical grounding states that "the individual subjected to habituation is each a single individual agent, and whatever affects him in any one line of activity, therefore, necessarily affects him in some degree in all his various activities" (Brette et al., 2014, p. 405). As such, the strength of car-use habit has been evaluated on the premise of its relations and consistency with other habits (Brette et al., 2014). For example, habits can be mutually strengthening, where the habit of driving to work is associated with other habits such as grocery shopping after work. The hesitation to adopt another alternative, such as 
public transit or ride-sharing services, can be explained by the fact that the habit of driving to work justifies the occurrence of grocery shopping after work, and vice versa (Brette et al., 2014).

Additional evidence from studies of travel behaviour where one habit triggers another can be illustrated through the car-use habit and listening to music, talking on the phone, and others (Brette et al. 2014). In light of these findings, the repetition of behaviour is interconnected with the strengthening of habits. Therefore, in order to enact change in individual travel behaviour, planners must act on the "various linked factors that underlie the development and strengthening of bundles of everyday life habits" (Brette et al., 2014, p. 417).

The Transtheoretical Model (TTM) is a comprehensive theory of change, conceptualizing the process of intentional behaviour change (Prochaska \& DiClemente, 1983; Prochaska et al., 1992). The stages of change can be applied to the complexity embedded in changing travel habits, where a predetermined modal choice is often adopted as the easier alternative. TTM's stages of change illustrate that change is a complex process which requires time and effort, where individuals often recycle through the stages or relapse to earlier stages, such as trying out carpooling with a coworker for a few weeks (Fig. 1).

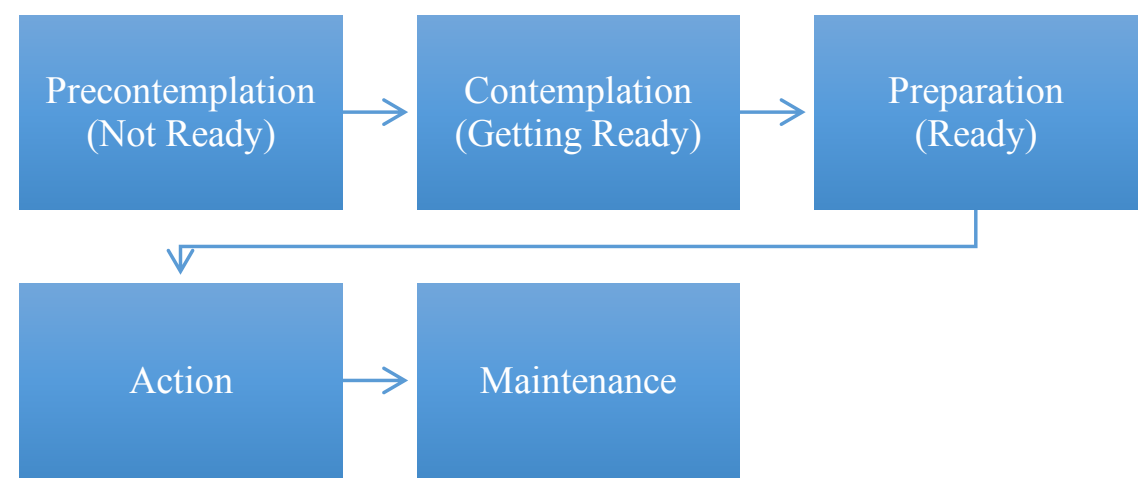

Fig. 1. TTM's Stages of Change 


\section{c. Policy Relevance}

Habit formation is occurring alongside utility, actively unravelling the nuances in how people make decisions. If planners simply accept a utilitarian view and assume that, among other things, AVs are going to reduce the in-vehicle travel costs, overly optimistic forecasts may result. Theory plays a significant role in practice, as the chosen theories to base planning decisions on have a direct impact on the resulting forecasts and subsequent investments.

Habit formation theory is premised on the existence of social processes which take time. It tempers expectations, in terms of how humans are going to behave, and it can act as a caveat on the implicit assumption that planners and policymakers need to act and invest now in order for planning outcomes to materialize.

Therefore, although it is necessary to conduct survey work and develop quantitative forecasts, the planning process does not merely end there. Rather than investing all efforts in the generation of new data to develop additional forecasts and scenarios, it is also important to engage with individuals on a personal level - whether this be through public technology demonstrations or focus groups - in order to learn about the public's opinions and desires.

\section{RESEARCH DESIGN}

\section{a. Methodology and Sample Characteristics}

Although theory suggests that seniors and individuals experiencing physical disabilities are likely to benefit from automated vehicles, the results from the GTHA Automated Vehicle 
Consumer Survey ${ }^{l}$ suggest that these groups are less likely to adopt AV technologies. As such, the disconnect between the theoretical and likely benefits and impacts of AVs illustrated through the quantitative findings confirmed the need for focus groups and informed their configuration.

In comparison to quantitative methods, the focus group methodology is better positioned to quickly collect rich information on a given topic, and to explore the intricacies of human decision-making and stories that are not necessarily communicated through quantitative findings. As such, the conversational nature of focus groups is useful in revealing the complexities of opinions, questions, and concerns of residents in the GTHA as they relate to AVs.

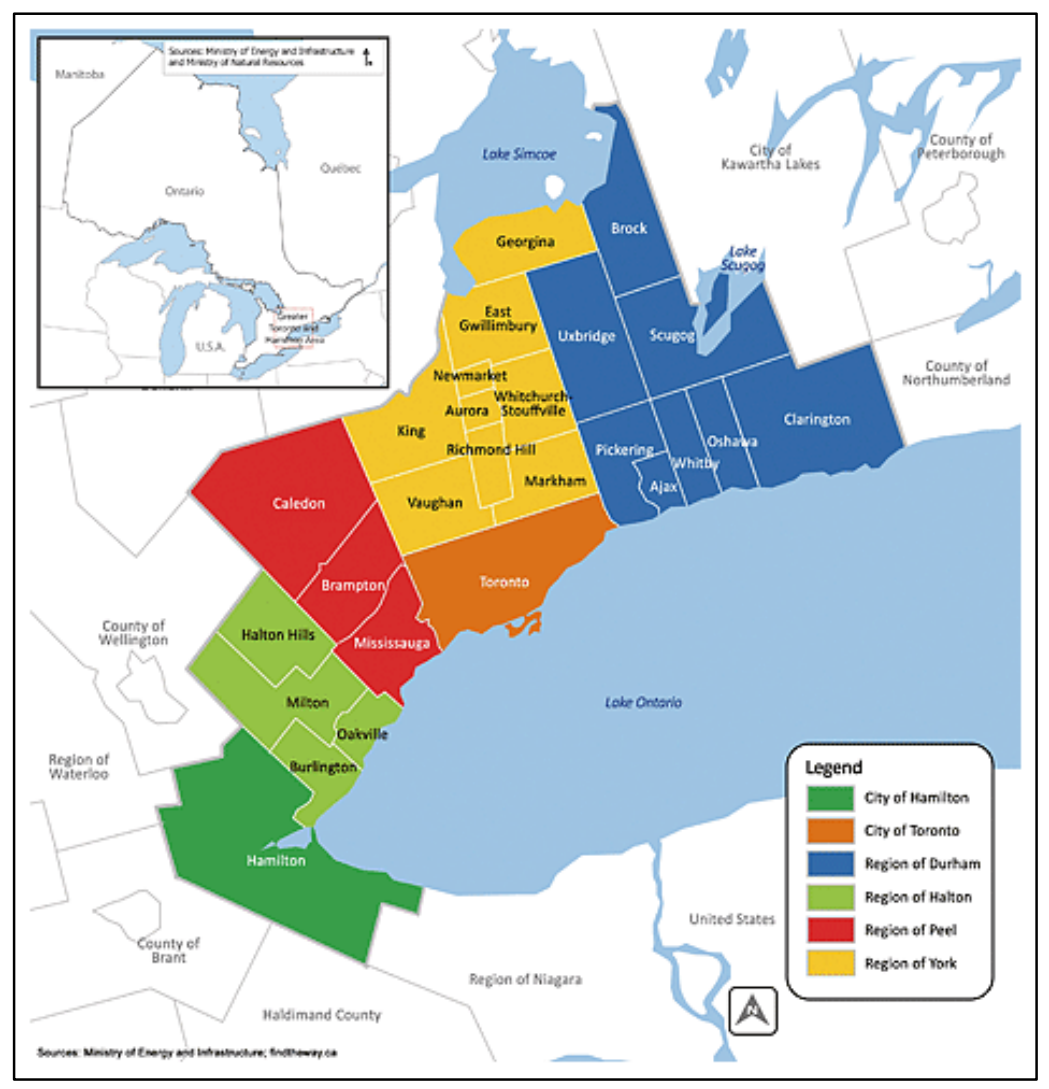

Fig. 2. GTHA Regional Map ${ }^{2}$

\footnotetext{
${ }^{1}$ The internet survey was conducted in November 2016 by graduate student Kailey Laidlaw and Dr. Matthias Sweet, as part of this research initiative.

${ }^{2}$ http://www.metrolinx.com/thebigmove/images/p4 map 475w.gif
} 
In May and June of 2017 and in January of 2018, the research team hosted five focus groups with residents of the GTHA to explore individual attitudes toward AVs and to discuss how they might use or interact with them as the technology becomes more available. With the primary objective to collect a wide range of opinions, five somewhat thematically distinct focus groups were recruited: individuals from the general public; seniors ( $>55$ years of age); individuals with accessibility needs; active transit users; and a suburban group from the City of Vaughan. Participants for the senior focus group were recruited from Ryerson's Chang School Senior and Community Engagement program. Participants for the general public group were recruited the GTHA Automated Vehicle Consumer Survey respondents. Participants for the active transit and accessibility focus groups were recruited from existing advisory groups maintained by Metrolinx ${ }^{3}$. Participants for the suburban focus group were recruited through public posters in community centres and public library locations throughout the City of Vaughan ${ }^{4}$. All participants were recruited from across the Greater Toronto and Hamilton Area.

Table 1. Focus Group Characteristics

\begin{tabular}{|c|c|c|}
\hline Focus Groups & Sample Description & Participant Turnout \\
\hline Focus Group 1 & Senior & 7 participants \\
\hline Focus Group 2 & General population & 6 participants \\
\hline Focus Group 3 & Active transit & 3 participants \\
\hline Focus Group 4 & Accessibility needs & 4 participants \\
\hline Focus Group 5 & Suburban & 9 participants \\
\hline
\end{tabular}

${ }^{3}$ Let Go Know Customer Panel and Metrolinx Accessibility Advisory Committee.

${ }^{4}$ The addition of the Vaughan focus group was determined in the fall of 2017 after revising the transcripts from the May and June focus groups. 
In reality, there was considerable overlap in group demographics, making the distinction between the original categories less important. The first four focus groups from May and June were generally more urban, Toronto-centered than would be expected based on the general population. For this reason, an additional focus group with Vaughan residents was facilitated in January of 2018 in order to collect missing information pertaining to the suburban perspective.

\section{b. Focus Group Programming}

Exploratory in nature, the focus group programming followed a semi-structured discussion with a series of open-ended questions. The questions were framed according to the three following topics: general interest in AVs; how AVs will be used; and broader policy implications of AVs. In light of these topics, a series of questions served as guides during the focus group discussions, including topics such as public familiarity with and attitudes towards AVs, preferred model (shared or privately owned AVs), relationship between AVs and other road users, and the expected role of government.

Half-way through the two-hour discussion, focus group participants were presented with a three-minute video of a legally blind individual travelling in Waymo's automated vehicle ${ }^{5}$. The purpose of presenting this video was to determine whether or not the opinions of participants would change before and after watching the video. Overall, the conversation across all focus groups was free-flowing and balanced, encouraging and allowing all participants to share their ideas and discuss among one another.

\footnotetext{
${ }^{5}$ Self-Driving Car Test: Steve Mahan. Youtube. https://www.youtube.com/watch?v=cdgQpa1pUUE. A version of the video in described audio was played for a focus group with visually impaired participants.
} 


\section{RESULTS}

\section{a. Analysis}

The data was analyzed using a thematic framework, identifying patterns and grouping quotations into general categories and subsequent sub-themes. Premised on the judgement of the primary author, this thematic framework proves useful for the analysis of qualitative data, as patterns and concepts are meticulously defined and the data's rich details are preserved (Huth et al., 2014; Braun \& Clarke, 2006).

Introduced by Braun and Clarke (2006), the framework follows six systematic steps (Fig. 3). As per the familiarisation phase (phase 1), the audio recordings from the focus group discussions were transcribed in full, consulting the recordings for additional clarifications when required. In order to uncover themes and patterns, the transcripts were revised in depth several times.
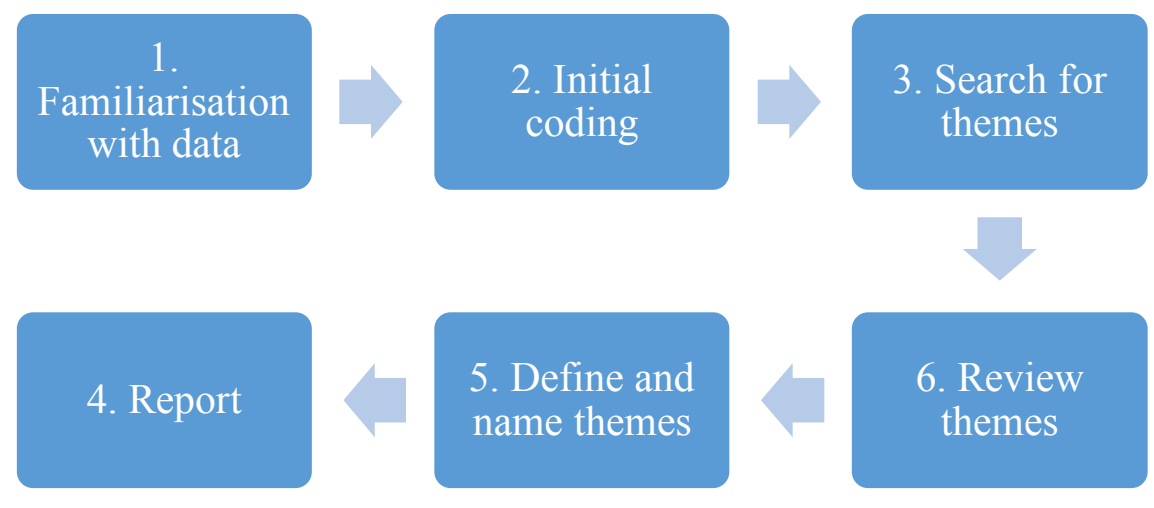

Fig. 3. Adapted thematic analysis framework from Braun and Clarke (2006)

In the initial coding phase (phase 2), the identified patterns from the focus group transcripts were classified into broad categories (i.e. concerns, benefits, regulation). Through these broad categories, six distinct themes were formulated in the subsequent phase (phase 3). 
The revision of the themes followed (phase 4) in order to ensure coherence and to verify supporting data for the subthemes. Final themes and subthemes were then defined (phase 5), followed by the reporting of findings (phase 6) through an analytic narrative including quotations from the focus group transcripts and argumentation informed by academic literature where applicable. It is important to note that the data from the five focus groups were analyzed as one comprehensive entity for the purposes of analysis, as differences in responses between the groups were infrequent.

\section{b. Themes and Findings}

Six themes were identified through the comprehensive analysis of the focus group transcripts, each accompanied by two subthemes. Although there are many important themes as they relate to $\mathrm{AVs}$, the focus group discussions were not able to address some topics as comprehensively as others, such as the technicalities involved in pricing schemes and willingness to pay.

The first theme is that of safety, including questions relating to cybersecurity and privacy (i.e. hacking), as well as physical safety concerns as they relate to riding in an AV. The second theme relates to traffic management and shared spaces, such as the logistics of traffic flow, street infrastructure, and the interactions between AVs and other road users (i.e. conventional vehicles, pedestrians, and cyclists). The particularities of ethics are discussed in the third theme, highlighting questions relating to liability and legal issues in the occurrence of an accident with an $\mathrm{AV}$, as well as discussions relating to the moral considerations to be made (or not) by AVs. The regulatory framework of AVs is discussed in the fourth theme, including the public's opinion on the roles and responsibilities to be played by the public and private sectors. The fifth 
theme explores the preferences in ownership models, whether it be shared AVs such as Uber style car-share services, or privately owned AVs such as Tesla vehicles. Finally, the expected benefits of AVs are discussed in the sixth theme.
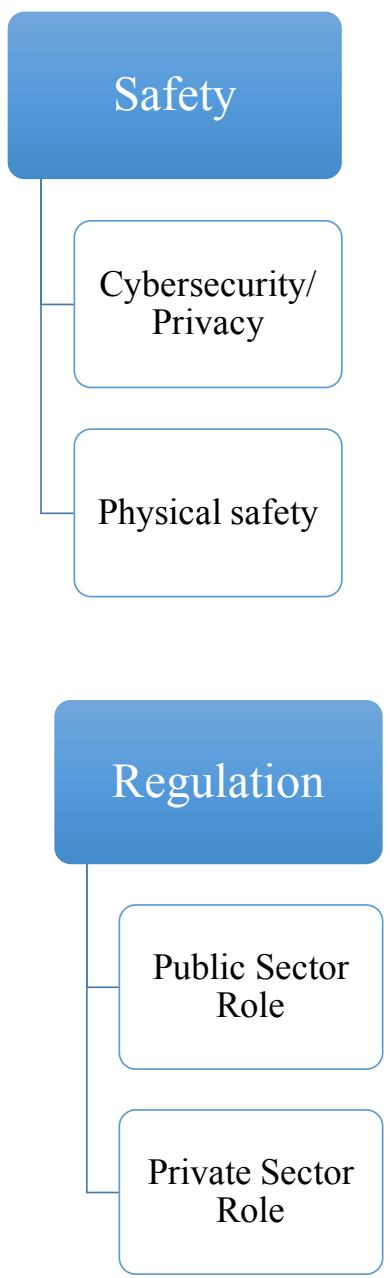
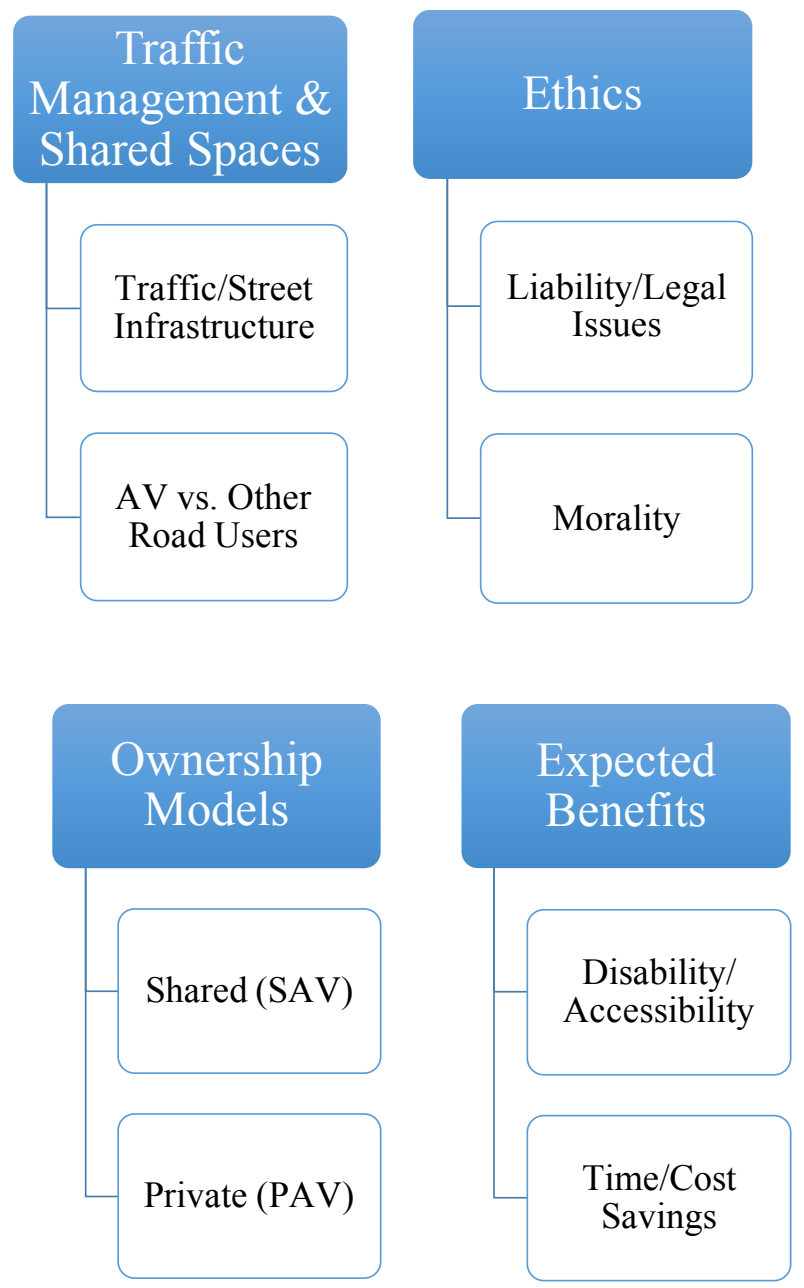

Fig. 4. Overview of themes and sub-themes from focus group discussions

\subsection{Safety}

Safety considerations are common across all focus groups, specifically relating to cybersecurity and privacy issues including the possibility of hacking, as well as physical safety concerns while riding in the vehicle. In terms of cybersecurity and privacy, a concern unique to 
$\mathrm{AVs}$ is that of hacking. This concern is raised in the context of the car "spying" on passengers, revealing personal data and potentially causing the vehicle to drive to unexpected locations.

"What if they suddenly stopped everybody's cars on the road as a protest or something."

"There was a virus last week. It's inevitable. Something will happen. But as a collective we will be a lot safer with the combined technology of the vehicle making the decision."

On one hand, some participants assume that AVs will be safer and more reliable than conventional vehicles with human drivers. Conversely, others worry about the occurrence of system failures such as technological glitches, which could potentially lead to malfunctions causing a collision or potentially leaving the passenger or vehicle owner stranded. There are similarities to be drawn from the airplane conundrum, where air travel is statistically proven to be overwhelmingly safer than driving a car ${ }^{6}$. However, the fear of airplane accidents among the general public is significant and perceived as catastrophic, despite it being irrational.

\section{"It will be a lot safer... Crazy drivers beside me freak me out. [AVs would have] 360 degrees' sensor, controlled by computer." \\ "Humans created technology, and sometimes things freeze or break down."}

Some participants indicate the potential for improved safety with AVs due to the elimination of human error, including distracted driving (i.e. texting and drunk driving). As such, participants expect that all traffic rules will be adhered to when riding in fully automated vehicles.

"There might be fewer distracted drivers. I think I might feel safer. They don't obey traffic rules, so this might make it better."

\footnotetext{
${ }^{6}$ Data from the US National Highway Traffic Safety Administration indicates that there were approximately 35,000 motor vehicle fatalities in 2015, while the National Transportation Safety Board records 27 total US airline accidents (zero fatalities) in the same year.
} 
Once individuals overcome their initial fear of the technology, - which often comes from first-hand experience riding in a vehicle and/or public education - their willingness to adopt increases. This observation is based on comments from participants actually riding in vehicles with autonomous capabilities in their own time.

"I've driven in a Tesla and once I drove in that, it convinced me that it knows what it was doing. I think that the initial fear is there, and until you experience one and overcome that fear, then the rest just falls into place."

However, the levels of agreement differ, as many participants approach the topic with caution, expressing that they would "wait and see" before adopting AV technologies themselves.

\section{"I need to make sure the safety issues have been worked out first. I don't want to feel like I'm a test pilot."}

Overall, the safety considerations of AVs are a common theme in all focus group discussions, with many concerned about hacking, while others highlighting the potential increased safety benefits of AVs.

\subsection{Traffic Management \& Shared Spaces}

Participants are interested in traffic management and how roads may physically look different with the introduction of AVs, from street infrastructure to traffic flow. In this line of thinking, most focus group participants are interested in how AVs will share the road with other users such as conventional vehicles, cyclists, and pedestrians, and how these interactions will unfold. Participants highlight the ways in which the built environment might change, speculating the possibility of high occupancy vehicle (HOV) equivalent lanes for AVs.

\section{"You may have different lanes for different people [using different modes]."}


"I don't understand [HOV] lanes. I don't understand how that works anyway. You've got to make your way through that clogged maze of general lanes to get in there, it's really hard."

In regards to the ways $\mathrm{AVs}$ will interpret the environment in which they operate, participants encourage the public sector to provide the necessary infrastructure for AVs to navigate safely within and outside city boundaries.

"Governments need to play their part to standardize things. If it's lines on the road, stop signs, municipalities have to play their role."

Discussions on traffic flow arose in all focus groups, discussing whether or not AVs would improve or worsen congestion on roads. Some believe that traffic flow will improve, indicating that AVs will drive more efficiently, while others question the impact on traffic flow as AVs and conventional cars will share the road.

"Would there be an advantage or would I still be stuck in traffic? In 20 or 50 years maybe if everybody is using a driverless car maybe it becomes more worth it but if it's just me in mixed traffic, I'm not sure."

How AVs might interact with other road users is a popular theme across all focus groups. Most discussions speculate how these interactions might unfold, highlighting both benefits and concerns.

"Whether I'm a pedestrian, making sure they stop before I cross. Driving next to one, I might try to speed up and get out of its way. I think it might make me a little more cautious."

"For me, when I come to a four-way stop, everybody gives each other eye contact and we know who goes first and understand things. That acknowledgment and you have everyone's O.K to go through. Driverless cars may not do that. [...] It'll take a while to adjust, like a reflex I guess."

Others question whether AVs will be able to seamlessly communicate with nonmotorized road users, with some suggesting that the presence of law-abiding AVs could indirectly encourage active travel behaviours such as cycling. 
"I'm concerned as a pedestrian and a cyclist. Removing the driver from the fray-is the pedestrian or cyclist safer? I'm worried about that."

"If I knew I'd be getting $1.5 \mathrm{~m}$ of clearance - I'd have more confidence walking or cycling. [Automated vehicles] would seem less likely to have a collision with me. If they're safer I might be more inclined to bike because it's safer."

In sum, participants expect the built environment to change in specific ways as to accommodate AVs on the roads, attributing the responsibility of standardizing the infrastructure to the public sector. Additionally, the majority of focus group participants expect a long transition period in becoming accustomed to interacting with AVs on the road.

\subsection{Ethics}

The arrival of automated vehicles presents many unanswered ethical questions, specifically relating to issues of morality and liability. Focus group participants have many questions pertaining to the difficult split-second decisions to be made by AVs.

\section{"Does the car protect its riders at all costs?"}

"If a biker or pedestrian steps out in front [of the car], the car has to make a decision. Is it going to protect what's inside and hit the person? Or it going to swerve, miss the pedestrian or biker and roll the car?"

With no human in the driver's seat, one participant questions whether or not car manufacturers are to be held responsible for a homicide. While AVs may reduce the potential for operation-related vehicle collisions, participants highlight that inevitable situations will arise and that technology will be in control of the ethical choices to be made in emergency situations, where some extent of harm is unavoidable.

\footnotetext{
"Does the car take the greater good and I experience the collision? Do you want the greater good? Or the best for me? It's one of those ethical conundrums that the car is deciding. "
} 


\section{"Legally correct and morally correct are different."}

Participants across all focus groups share concerns about liability and legal issues including licensing and insurance regulations, as well as questions surrounding the determination of responsibility in the event of a collision.

"What would the liability be for a driverless car? [...] Who gets the demerit points? If companies can't increase insurance rates and demerit points, the revenues from insurance might be reduced."

\subsection{Regulation}

All focus groups discuss the extent to which the public sector should be involved in regulating AVs. Participants are vocal in expressing that public policy will shape how AVs are implemented and used, while also acknowledging the role of the private sector. Common statements include the necessity of regulating and standardizing the driverless technology across all vehicle manufacturers in order to ensure compatibility across systems.

"You couldn't have Ford program it one way and GM program it another way and Tesla another way ... there needs to be some kind of universal interface."

Participants highlight opportunities for AVs to be integrated with public transit, and hypothesize ways in which municipalities can be involved in the regulation.

"[Metrolinx] could have driverless cars in the area so people don't have to drive to the station at all. They could have driverless cars pick people up at home and drop them off at the station and then the car goes to pick somebody else up."

Participants support the notion of strong AV regulations from the public sector, but remain wary of too much government intervention. There is some consensus that when AVs are in their first implementation phases on public streets, the government will have to establish 
certain regulations such as minimum age requirements for passengers. Overall, focus group participants expect the public sector to define and enforce the regulations.

"If companies can't increase insurance and demerit points, the revenues from insurance might be reduced. The public sector / government needs to define the rules for this. Everyone would say that they are not at fault, but the public sector would need to define the rules."

"If Ontario has a policy but Québec doesn't acknowledge that, then can you drive to Montréal? Is your driverless car only valid in Ontario? And who is responsible for that? Who is the universal body who creates these rules and guidelines?"

At the same time, some participants raise concerns regarding over-regulation.

"If you have too much regulation, it will become inefficient."

All participants generally agree that the public sector and government have a responsibility to educate the public on AVs. Among other reasons, public education can potentially mitigate against existing concerns and questions, and thus be useful in providing information on the details of the technology, how AVs are used in different jurisdictions, and what services are available.

"I came in this room with all kinds of questions and I still have lots of questions. The industry is not helping the public understand the technology. I'm not sure that the industry is educating people like me on what this might be like."

\subsection{Ownership Models}

With the exception of the suburban focus group, participants indicate significant interest in using shared AVs, similar to services like taxis and Uber, but indicate very little interest in paying more for such services. Many prefer the idea of having immediate access to an AV rather than owning one privately.

\footnotetext{
"No, I don't want one parked in my driveway. I want to call one up."
} 
"When I think about these driverless cars constantly picking people up or driving around wellused routes, that makes sense to me. You're not storing a vehicle back home."

Participants from the suburban focus group communicate a preference for the private ownership model. When probed with the question of carpooling, participants indicate that they would prefer a private experience over a shared one. Despite this, for-hire automated vehicles are viewed as a potentially more viable alternative for low-ridership transit services in suburban contexts.

"Sometimes you see the buses running with no one inside them. I think with driverless cars available, fewer people would use the bus."

On the theme of carpooling, discussions from the accessibility focus group reveal additional layers of complexity when considering vehicles that can accommodate wheelchairs and other mobility devices. In comparison to current public transit options, AV trips may have similar or more restrictive limitations.

"If you want to go with a group of people. That's another thing that you can't do very well on public transportation. If there are three of you who have mobility devices, it currently does not work at all."

The perceived costs-savings of using shared AVs is a key motivating factor for shared adoption, such as avoiding parking fees and expenses related to routine vehicle maintenance. Many participants indicate that they try to avoid driving downtown because of traffic and the high cost of parking, and rather use transit or car-sharing modes of transportation for downtown trips. It is also worth noting that the shared model appeals to those who are concerned that the arrival of AVs might result in greater volumes of vehicles on the road.

"If I'm going downtown, the car stays home. If I'm going outbound I'm going by car." 
"I don't like the idea of all the roads being full of driverless cars with just one person in them. That could happen, especially if people bought them."

Although the preference for a shared ownership model is apparent across most focus groups, some participants remain apprehensive.

"You're going to be with other people. And when you're used to being the driver, on your own, in your own car, good or bad, it's quite a leap to say now I'll be sharing, or communal."

5.6 Expected Benefits

Participants commonly cite benefits of AVs as increased safety, increased productivity and convenience (i.e. the ability to work, sleep, talk, and eat while traveling), as well as costs savings. Many speculate that their individual travel behaviour could potentially change due to $\mathrm{AVs}$, indicating that AVs would allow them to travel to further destinations that are not accessible by bus.

"If there was a driverless car and I didn't have to park, I might take that. I would be more inclined to go somewhere."

"I would end up in a car more often than I do now because it's a more pleasant experience. The fatigue and boredom of long drives would be gone for me"

Across all focus groups, the major expected benefit of AVs relates to the increased mobility it presents for target populations such as seniors and individuals with physical disabilities. Participants with mobility constraints from the accessibility and senior focus groups are very enthusiastic about the freedom and independence AVs could bring to their daily lives, such as the possibility of sending a vehicle to pick up their groceries. Findings suggest that accessibility may be maintained despite mobility constraints by on-demand AV services used to deliver goods and services to individuals. 
"At some point they will take away my license but I'll still be able to go where I want. This is a great solution for older people."

"You can't take anything with you on public transit. If a shared vehicle system were available, it would aid me in grocery shopping. I would go to the grocery store and load up everything I need - for weeks! - and put it in the car and take it home. As it is now I get a friend, or I take the bus and walk. So I depend on somebody else."

There was consensus in all focus groups that participants could see the benefits that AVs may have for other groups - individuals with mobility constraints and commuters who drive to work every day - whether or not they expect personal benefits.

"There are so many reasons why a person might not be able to drive a regular car and why public transportation can be really annoying. So this is a really great way for people who can't drive normally to be able to get around."

"[A relative] is blind. She's so reliant on her husband. This would give her some freedom, some independence. It would change her life."

"I still want to drive. If I don't have a place to be at a certain time that's ok with me. I mean I hate the way traffic has gone in the city. It's impossible. And I feel very badly for the people that have to be somewhere, like a job for example."

Despite their recognition of potential benefits, participants in the accessibility focus group express concerns regarding the technicalities of the first and last one hundred meters of a given trip.

"If you're visually impaired, you might have no idea where you were. Are you at the end of the lot or the front? How do you get out and find the mall of where you're going to - how do you know where you are?"

6. DISCUSSION

Overall, focus group participants are curious about AVs and their opinions are still emerging. Key questions include road safety, cybersecurity as it relates to hacking, the travel experience, the moral dilemmas, and the interaction between AVs and other road users. The 
majority of participants indicate a preference for the shared model of AVs, even though they would use them infrequently, especially for special trips (i.e. further destinations, errands, etc.). In suburban Vaughan, participants express a preference for the private AV experience but are uninterested in paying more for them, and generally agree that AVs may replace public transit in the suburban context, especially in pockets with low ridership. Across all focus groups, most expect future transportation systems to include hybrid fleets of conventional vehicles, semiautonomous vehicles, fully automated vehicles, pedestrians, cyclists, and transit users.

Most focus group participants expect significant benefits from AVs, specifically for providing independence and mobility options for seniors and individuals with physical disabilities. However, interesting concerns are raised regarding drop off locations for individuals with mobility issues. Participants from the accessibility focus group highlight the fact that many individuals with mobility restrictions have, through trial and error, created personal mental maps for navigating regular destinations, and question the role of AVs in facilitating or disrupting these habits.

For most focus group participants, the regular use of automated vehicles remains a distant, almost idealized 'pie-in-the-sky' scenario. Despite this, findings suggest that a future where automated vehicles are commonplace is most tangible to individuals from the accessibility group. For individuals with physical disabilities, the potential future of AVs brings its own sources of opportunities and issues. This group highlights very detailed applications of how they will use AVs, whether it is the ability to pick up groceries, to travel greater distances with room for baggage and supplies, and the opportunity and physical space to bring equipment and supplies to work related events. Related to the nature and complexity of their conditions, 
individuals with physical disabilities must consider the fine-grained details of every trip, from entering the vehicle to getting through the front doors of their final destination.

As demonstrated by the expressed curiosity and caution of focus group participants, public education will play a pivotal role in building public trust. Consistent with findings from literature involving focus group research, most participants left the two-hour discussions feeling more accepting and eager to learn more, which highlights the importance of and need for on-going engagement on the topic. Conversely, because habits take time to change, incremental approaches should be adopted for the introduction of AVs on city streets, through a series of pilot projects. Through incremental approaches, it is recommended that planners follow the technological breakthroughs, encourage research and local testing, and play an active role in educating the public on AVs.

So what does this mean for planners in the short-term? Since the mass adoption of AVs is dependent on public acceptance, it is within the planner's responsibility to engage in consultations internally, within organizations and across departments, as well as externally, with stakeholders and members of the community. On-going consultations will ensure collaboration across stakeholders, build trust among the public, and increase comfort levels over time.

Embracing 'trial and error' scenarios will be important, where a municipality may initially decide to experiment with an automated shuttle bus, for example. Planners may not reach a consensus in every case, and what works in one region may not work in another. The role of planners will require incremental actions, public education engagements and positive pilot project demonstrations. 


\section{CONCLUSION}

Evidence from focus groups conducted with residents from the GTHA illustrate the imperative to study human decision-making and the process of acceptance of new technology in order to appropriately develop plans and policies for an automated future. Individuals are interested in learning more about the technology but remain reluctant to change their travel habits. Findings emphasize a need for policymakers to focus their efforts on AVs as an object of action, in order to determine how to regulate this technology for the greater good.

In general, participant responses reveal that habits are strong, especially as they relate to car-use, and that individuals are inclined to avoid situations of uncertainty as characterized by automated vehicles. While the significant benefits of AVs are expected for individuals with mobility constraints, many nuances remain relating to the technicalities of getting individuals in and out of the vehicles and to their final destinations.

In light of these findings, education presents itself as a critical component in addressing public willingness to incorporate AVs into daily travel habits. In order to facilitate the seamless integration of AVs into existing transportation networks and to mitigate challenges, on-going education within organizations and with communities will be essential. Consistent public engagement by industry (auto manufacturers and tech companies) and government (municipal and provincial) will assist in increasing trust and comfort levels among the public, in turn allowing for the potential benefits of AVs to be materialized.

In Ontario, the establishment of regulatory frameworks for AVs are in progress, with several research and controlled testing initiatives in place. A series of workshops led by the City 
of Toronto are currently occurring with the objective of gathering a diversity of opinions from key stakeholders across the city -from environmental groups to transit service providers- which will inform the next version of Toronto's Tactical Plan for automated vehicles. Policymakers and planners should engage in continuous learning to identify opportunities, consistencies, and inconsistencies as they arise in order to leverage AV policies that will advance broader planning objectives. 


\section{REFERENCES}

Adjei, E., \& Behrens, R. (2012). Travel Behaviour Change Theories and Experiments: A Review and Synthesis. Abstracts of the $31^{\text {st }}$ Southern African Transport Conference, 55-69.

Ajzen, I. (1991). The theory of planned behavior. Organizational Behavior and Human Decision Processes, 50(2), 179-211.

Alessandrini, A., Campagna, A., Delle Site, P., Filippi, F., \& Persia, L. (2015). Automated Vehicles and the Rethinking of Mobility and Cities. Transportation Research Procedia, $5,145-160$.

Bansal, P., Kockelman, K. M., \& Singh, A. (2016). Assessing Public Opinions of and interest in New Vehicle Technologies: An Austin Perspective. Transportation Research Part C: Emerging Technologies, 67, 1-14.

Bansal, P., \& Kockelman, K. M. (2015). Are We Ready to Embrace Connected and Self-Driving Vehicles? A Case Study of Texans. Transportation, 44, 1-35.

Bentham, J. (1890). Utilitarianism. London: Progressive Publishing Company.

Braun, V., \& Clarke, V. (2006). Using thematic analysis in psychology. Qualitative Research in Psychology, 3(2), 77-101.

Brette, O., Buhler, T., Lazaric, N., \& Marechal, K. (2014). Reconsidering the nature and effects of habits in urban transportation behavior. Journal of Institutional Economics, 10(3), 399426.

Daziano, R., Sarrias, M., \& Leard, B. (2016). Are consumers willing to pay to let cars drive for them? Analyzing response to autonomous vehicles. Resources for the Future, Discussion Paper, 16-35.

Google. (2012, March 28). Self-Driving Car Test: Steve Mahan. [Video File]. Retrieved from: https://www.youtube.com/watch?v=cdgQpa1pUUE

Huth, V., Füssl, E., \& Risser, R. (2014). Motorcycle riders' perceptions, attitudes and strategies: Findings from a focus group study. Transportation Research Part F: Traffic Psychology and Behaviour, 25, 74-85.

Kahneman, D. (2011). Thinking, fast and slow. New York: Farrar, Straus and Giroux.

Kyriakidis, M., Happee, R., \& de Winter, J. (2015). Public opinion on automated driving: Results of an international questionnaire among 5,000 respondents. Transportation Research Part F: Traffic Psychology and Behaviour, 32, 127-140. 
LaMondia, J.J., Fagnant, D.J., Qu, H., Barrett, J., \& Kockelman, K. (2016). Long-Distance Travel Mode-Shifts Due to Automated Vehicles: A Statewide Mode-Shift Simulation Experiment and Travel Survey Analysis. Transportation Research Board 95 ${ }^{\text {th }}$ Annual Meeting, Washington DC.

Litman, T. (2018). Autonomous Vehicle Implementation Predictions: Implications for Transport Planning. Victoria Transport Policy Institute.

National Highway Traffic Safety Administration. (2017). Quick Facts 2015. U.S. Department of Transportation, DOT HS 812 348. Retrieved from: https://crashstats.nhtsa.dot.gov/Api/Public/ViewPublication/812348

National Transportation Safety Board. (2017). Accident Summary for Major Segments of US Civil Aviation CY 2015. Federal Aviation Administration. Retrieved from: https://www.ntsb.gov/investigations/data/Pages/AviationDataStats2015.aspx

Nordhoff, S., Arem, B.V., \& Happee, R. (2016). A Conceptual Model to Explain, Predict, and Improve User Acceptance of Driverless Vehicles. The $95^{\text {th }}$ Annual Meeting of the Transportation Research Board, Washington DC.

Olsen, T., Laidlaw, K., \& Sweet, M. (2018). Automated Vehicles in the Greater Toronto Hamilton Area: Results from a 2016 Consumer Survey - Data Overview (Part B). Toronto: Ryerson University.

Prochaska, J.O., \& DiClemente, C.C. (1983). Stages and processes of self-change of smoking: Toward an integrative model of change. Journal of Consulting and Clinical Psychology, $51,390-395$.

Prochaska, J.O., DiClemente, C.C., \& Norcross, J.C. (1992). In search of how people change: Applications to the addictive behaviors. American Psychologist, 47, 1102-1114.

Robertson, R.D., Meister, S.R., \& Vanlaar, W.G.M. (2016). Automated Vehicles: Driver Knowledge, Attitudes, and Practices. Traffic Injury Research Foundation.

Simon, H.A. (1955). A Behavioural Model of Rational Choice. The Quarterly Journal of Economics, 69, 99-118.

Thaler, R.H., \& Sunstein, C.R. (2009). Nudge: Improving Decisions about Health, Wealth, and Happiness. London: Penguin Books Ltd.

Yim, Y. (1997). A Focus Group Study of Automated Highway Systems and Related Technologies. California PATH Working Paper, Berkeley: University of California.

Zmud, J., Sener I, N., \& Wagner, J. (2016). Revolutionizing Our Roadways Consumer Acceptance and Travel Behavior Impacts of Automated Vehicles. Texas A\&M Transportation Institute. 